\title{
Nitroglycerin/Sodium Citrate/Ethanol Solution
}

National Cancer Institute

\section{Source}

National Cancer Institute. Nitroglycerin/Sodium Citrate/Ethanol Solution. NCI Thesaurus.

Code C124659.

An antimicrobial lock solution (ALS) containing the nitrate nitroglycerin, sodium citrate and ethanol, with potential antimicrobial and anticoagulant activities. Upon application to the catheter as an ALS, the nitroglycerin is converted into nitric oxide (NO), which exerts antimicrobial activity. The citrate exerts anticoagulant activity, thereby preventing blood clotting and occlusion and maintaining the fluidity of the administered solution. In addition, both citrate and ethanol exert antimicrobial activity. This may prevent bacterial colonization on the surface of the catheter, biofilm formation and prevents catheterassociated infections. 